'Breeding for Success: Diversity in Action' C.F. Mercer (ed).

Proceedings of the $13^{\text {th }}$ Australasian Plant Breeding Conference,

Christchurch, New Zealand 18-21 April 2006. pp. 520-525.

\title{
Plant and endophyte genotype affects peramine concentrations in ryegrass/endophyte associations.
}

\author{
Lester Fletcher $^{1}$ Syd Easton ${ }^{2}$, Alison Popay ${ }^{3}$, Brian Tapper ${ }^{2}$ and David Hume ${ }^{2}$ \\ ${ }^{1}$ AgResearch Lincoln, PO Box 60 Lincoln, New Zealand \\ ${ }^{2}$ AgResearch Grasslands, PB 11008 Palmerston North, New Zealand \\ ${ }^{3}$ AgResearch Ruakura, PB 3123 Hamilton, New Zealand
}

Abstract. Peramine concentrations in a range of ryegrass/ AR1 endophyte associations have been measured during pre-market safety testing. While concentrations for diploid perennial ryegrass cultivars were in excess of $15 \mathrm{ppm}$ a small number of associations were below $10 \mathrm{ppm}$. These proved to be tetraploid ryegrass. When assessing the effectiveness of a ryegrass/AR1 association to deter ASW, and other invertebrate pasture pests, the host ryegrass cultivar or genotype and consequent peramine concentrations need to be taken into consideration.

\section{Introduction}

The forage grasses, ryegrass (Lolium spp.) and tall fescue ( Festuca arundinacea L), form natural, mutualistic associations with endophytic fungi, which is important for the survival of both participants. In these mutualistic associations the endophyte is transmitted vertically via the seed of the host.

Neotyphodium spp. endophytes infecting ryegrass and tall fescue have an extraordinary impact on the ecology and economy of pasture by increasing the fitness and survival of the host grass. This is mediated via the production of a range of secondary metabolites with anti herbivore activity.

At least four classes of anti-herbivore alkaloids produced in grass/endophyte associations have been identified and characterised. There are likely to be many other metabolites produced by wild-type ryegrass and tall fescue/endophyte associations, but these currently appear to be of little consequence in our current grazing systems.

Two classes of endophyte alkaloids, indole diterpenes (lolitrems etc) and ergot alkaloids (such as ergovaline) possess both anti-insect and anti-vertebrate activities. In fact animal toxicity caused by endophytes is probably the oldest known example of extrinsic anti-quality factors of forage (Bacon and Hill 1995). The pyrrolopyrazine alkaloids (peramine etc) and the pyrrolizidine alkaloids (lolines, produced in tall and meadow fescue but not in perennial ryegrass) do not appear to be toxic to vertebrates.

The activity of peramine as a feeding deterrent can significantly enhance competitiveness of grasses with endophytes that produce it. Peramine is a powerful feeding deterrent to adult Argentine stem weevil (ASW, Listronotus bonariensis, an important pasture pest in New Zealand) (Rowan et al. 1990) and is the major Neotyphodium metabolite influencing ASW behaviour toward individual plants. Maintaining a high peramine concentration estimated to be a minimum of between 15 and 20 ppm (Popay and Wyatt 1995) is therefore crucial for strong resistance to ASW.

Apart from ASW, the efficacy of peramine against other insect pests has only been determined by comparing different grass/endophyte associations producing or not producing peramine, rather than a direct response of the insect to pure peramine in the diet.

As knowledge of endophytes and their host relationships increased, the potential to exploit the diversity in alkaloid production, or expression, to maintain insect 
deterrence and reduce toxicity to livestock was soon recognised (Latch 1989). Grass/endophyte associations that produce bio-protectants without the toxicity to grazing livestock became a target for forage improvement. The potential became realisable when Latch and Christensen (1985) developed a method for inoculating endophyte-free ryegrass seedlings with selected endophyte strains.

The first screening criterion was to identify and isolate endophytes which did not produce ergovaline or lolitrem B in association with their host but did produce effective levels of peramine. This eventually resulted in the development and marketing of numerous ryegrass cultivars with the non-toxic endophyte, AR1 (Fletcher 2005). These associations resulted from selection that focused on variation in alkaloidproducing properties of the Neotyphodium lolii genome.

Similar success has been achieved by selecting within the tall fescue endophyte Neotyphodium coenophialum, albeit for a different alkaloid profile. However the host grass genotype can also have a significant impact on the expression, or concentration, of grass/endophyte metabolites.

Several examples of plant genotype having a significant influence on response of invertebrate pests, or more directly on the alkaloid profile, of grass/endophyte associations have been reported (Agee and Hill 1994, Breen 1994, Latch 1994, Ball et al. 1995, Latch 1998, Assuero et al. 2000, Faeth et al. 2002, Popay et al. 2003). A deliberate selection within a tall fescue population infected with a common strain of wild-type endophyte $N$. coenophialum resulted in a three-to six-fold reduction in ergovaline concentrations (Agee and Hill 1994) and a similar degree of variation in alkaloid concentrations in ryegrass was reported by Ball et al. (1995).

Arizona fescue Festuca arizonica, with its wild-type endophyte Neotyphodium starri, produces peramine, but concentrations can be significantly influenced by the host plant genotype (Faeth et al. 2002). Popay et al. (2003) also found a ryegrass cultivar effect on peramine, with consequent differences in the level of resistance to ASW damage. They found the tetraploid and hybrid ryegrass cultivars sustained more ASW damage than the diploids and perennials. They linked differences in feeding damage to the different concentrations of peramine in the leaf lamina.

The grass host genotype can thus influence the production, or expression, of endophyte alkaloids although it is unlikely to eliminate the production of any given alkaloid, as can be achieved through selected endophytes. This has lead to selection programmes to reduce the concentration of ergot alkaloids to a level non-toxic to, or less toxic to, grazing livestock while retaining effective concentrations for insect deterrence (Agee and Hill 1994). Ryegrass endophyte associations developed using this concept are being marketed in New Zealand (M Norriss, pers. comm.).

More recently, failure to support effective peramine production has been found in some associations of ryegrass cultivars infected with AR1. While this clearly does not pose any threat in terms of toxicity to animals, it could have a significant impact on host plant survival, especially under high invertebrate pest pressure.

During routine testing of a number of ryegrass cultivars with the same endophyte, AR1, some cultivars were found to have significantly lower concentrations of peramine, compared to wild-type controls.

\section{Methods}

Replicated paddock trials were established in three seasons to compare associations of AR1 endophyte with ryegrass cultivars. Plots were sown with seed of known high 
endophyte infection, and infection rates of the resulting swards were monitored. The number of cultivars/candidates with AR1 varied with each trial, but all trials were managed in the same way. Environmental conditions were the same within trials, but not between trials so valid comparisons can only be made between candidates in any one trial. There were three paddock replicates of each candidate/cultivar with AR1. In summer and autumn eight randomly selected herbage samples from each paddock, were cut to ground level, bulked, freeze dried then ground through a 1mm screen. Samples for each plot and season were then individually assayed for peramine concentrations, and processed in the laboratory as one batch for each trial.

\section{Results and discussion}

Overall, mean peramine concentrations were lower than reported in some other studies. This may be in part due to season, maturity of herbage, and spatial distribution of peramine in ryegrass tissues. The highest concentrations are usually found in the youngest leaves, in summer or early autumn, with much lower levels in leaf sheath and mature herbage. Samples analysed for this study were total above-ground mature herbage.

Most cultivars did not differ significantly from control treatments with wild-type endophyte (Table 1). However four cultivars had significantly lower concentrations of peramine, falling below the 15-20ppm minimum threshold for effective deterrence of ASW (Popay and Wyatt 1995). These results are in agreement with those of Easton, et al. )2002), Faeth et al. (2002), and Popay et al.(2003) who all reported the influence of the plant genome on peramine production or expression. In this study the three cultivars with low peramine levels were tetraploids, and one a hybrid. This accords with the observations of (Popay et al. 2003).

While there were minor variations among cultivars for the percentage of ryegrass tillers with viable endophyte, there was no significant correlation between the proportion of tillers infected and peramine concentrations. However this does not preclude the possibility that variations in mycelial mass, within tillers or plants, influenced peramine concentrations (Easton et al. 2002).

The results thus indicate that diploid perennial ryegrass cultivars are satisfactory hosts in terms of peramine production, but that artificial autotetraploids and possibly some hybrids may not be. While the AR1 endophyte strain is not found naturally in New Zealand, it produces peramine in New Zealand perennial ryegrass cultivars comparable with that produced by naturally occurring, presumably co-adapted, wildtype strains. However, the tetraploid host environment is sufficiently different for endophyte metabolism to be perturbed.

To date the development of non-toxic ryegrass endophyte associations, such as those with AR1, has been via selection/breeding of elite plant germplasm and then inoculating this material with a selected endophyte (AR1), just prior to commercial release. The plant and endophyte germplasm have thus been selected/bred independently. This has been effective in the associations developed to date, but since both partners contribute to the association there is a risk of reduced compatibility, lower transmission rates via seed and less than optimum metabolite concentrations, all contributing to a less vigorous association. The low peramine concentration in the herbage of some associations reported here is an example of this. The grass and endophyte partners in natural associations have co-evolved as a unit over time resulting in robust mutualistic associations. On this basis, when developing new synthetic non- 
toxic endophyte associations, it would seem prudent to inoculate a range of grass germplasm with a selected endophyte/s then breed and select within this combined germplasm pool for the desired traits. This is likely to result in a more robust and stable association with more predictable attributes in the field.

In particular, autotetraploid breeding populations, developed primarily to deliver enhanced palatability to livestock, need attention if the robustness farmers have come to expect from endophyte infection is to be achieved.

\section{Future}

Although it is not proven, examination of data for variation in peramine concentrations usually proceeds as though "more peramine is better," but there may be an upper threshold and of course excessively high levels may reduce palatability to grazing livestock.

While minimum threshold concentrations of peramine for effective deterrence of ASW have been established, a maximum threshold, above which no added deterrence occurs, has not been established for this pest, or any pests which may challenge the host plant. Such a threshold is likely to vary for different insect pests. The examples of Popay et al. (2003) and the study reported in this paper have shown reduced concentrations of peramine compared with wild-type controls. Assuming the principle that "more is better" is valid, then increasing peramine concentration may be a viable objective for future "non-toxic" grass/endophyte associations. However, there have been no reports of attempts to increase peramine levels through selected endophyte strains, or selection within ryegrass host populations.

This paper has focussed on the influence of the endophyte and grass germplasm on the concentration of the insect pest deterrent, peramine.

It has become evident that there are other endophyte metabolites with bioactivity against invertebrate pests, so future selection criteria for "elite associations" are likely to be revised. Some new endophyte metabolites, which appear to be non-toxic to grazing livestock, have been characterised and studied while others are known only by the responses of invertebrate pests and grazing livestock to selected grass endophyte associations. As other metabolites become better understood, it may prove advantageous to eliminate, reduce or enhance their production. It can be expected that, as for peramine, both endophyte and host will influence concentrations in herbage. 
Table 1. Peramine concentrations (ppm) in a range of ryegrass cultivars with AR1, compared to ryegrass with its wild-type endophyte.

\begin{tabular}{|c|c|c|c|c|c|c|c|c|c|c|c|c|}
\hline \multirow[b]{2}{*}{ Trial 1} & \multirow[b]{2}{*}{$\begin{array}{c}\text { Wild-type } \\
\text { Control }\end{array}$} & \multicolumn{11}{|c|}{ Cultivar with AR1 } \\
\hline & & 1 & 2 & 3 & 4 & 5 & 6 & 7 & 8 & 9 & 10 & 11 \\
\hline $\begin{array}{l}\text { Peramine } \\
\text { conc. } \\
\text { LSD = }\end{array}$ & $\begin{array}{r}17.0 \\
\mathrm{P}=0.05)\end{array}$ & 17.2 & 17 & 16.2 & 15.2 & 14.8 & 14.2 & 14.1 & 12.2 & 12.0 & 9.5 & $\begin{array}{c}4.5 \\
*\end{array}$ \\
\hline
\end{tabular}

Trial 2

Peramine

conc.

$\mathrm{LSD}=8.0(\mathrm{P}=0.05)$

Trial 3

Peramine

21.4

conc.

$\mathrm{LSD}=7.2(\mathrm{P}=0.05)$

18.0

\begin{tabular}{cccccc}
$\mathbf{1 2}$ & $\mathbf{1 3}$ & $\mathbf{1 4}$ & $\mathbf{1 5}$ & $\mathbf{1 6}$ & $\mathbf{1 7}$ \\
\hline 18.0 & 17.2 & 15.1 & 15.1 & 12.1 & $8.2 *$
\end{tabular}

\begin{tabular}{ccccccc}
$\mathbf{1 8}$ & $\mathbf{1 9}$ & $\mathbf{2 0}$ & $\mathbf{2 1}$ & $\mathbf{2 2}$ & $\mathbf{2 3}$ & $\mathbf{2 4}$ \\
\hline 26.0 & 20.7 & 18.0 & 17.0 & 16.5 & $\begin{array}{c}10.8 \\
*\end{array}$ & $\begin{array}{c}7.4 \\
*\end{array}$
\end{tabular}

* Significantly lower in peramine concentration than the wild-type control $(\mathrm{P}<0.05)$.

\section{References}

Agee CS, Hill NS (1994) Ergovaline variability in Acremonium-infected tall fescue due to environment and plant genotype. Crop Science 34, 221-226.

Assuero SG, Matthew C, Kemp PD, Latch GCM, Barker GM, Haslett SJ (2000)

Morphological and physiological effects of water deficit and endophyte infection on contrasting tall fescue cultivars. New Zealand Journal of Agriculture Research 43, 49-61.

Bacon CW, Hill NS (1995) Symptomless Grass Endophytes: Products of coevolutionary symbioses and their role in the ecological adaptation of infected grasses. In: Systematics, Ecology and Evolution of Endophytic Fungi in Grasses and Woody Plants. S.C. Redlin (ed.). (American Phyopathological Society, St. Paul, MN).

Ball OJP, Prestidge RA, Sprosen JM (1995) Interrelationships between Acremonium lolii, peramine, and lolitrem B in perennial ryegrass. Applied and Environmental Microbiology 61, 1527-1533.

Breen JP (1994) Acremonium endophyte interactions with enhanced plant resistance to insects. Annual Review of Entomology 39, 401-423.

Easton HS, Latch GCM, Tapper BA, Ball OJP (2002) Ryegrass host genetic control of concentrations of endophyte-derived alkaloids. Crop Science 42, 51-57.

Faeth SH, Bush LP, Sullivan TJ (2002) Peramine alkaloid variation in Neotyphodiuminfected Arizona fescue: Effects of endophyte and host genotype and environment. Journal of Chemical Ecology 28, 1511-1526.

Fletcher LR (2005) Managing ryegrass-endophyte toxicoses. Neotyphodium in coolseason grasses (eds. Roberts, C.A, C.P. West and D.E. Spiers), 229-241.

Latch GCM (1994) Influence of Acremonium endophytes on perennial grass improvement. New Zealand Journal of Agriculture Research 37, 311-318.

Latch GCM (1998) Grass endophytes as a model. Sydowia 50, 213-228.

Latch GCM, Christensen MJ (1985) Artificial infection of grasses with endophyte. Annuals of Applied Biology 107, 17. 
Popay AJ, Hume DE, Davis KL, Tapper BA (2003) Interactions between endophyte (Neotyphodium spp.) and ploidy in hybrid and perennial ryegrass cultivars and their effects on Argentine stem weevil (Listronotus bonariensis). New Zealand Journal of Agriculture Research 46, 311-319.

Popay AJ, Wyatt RT (1995) Resistance to Argentine stem weevil in perennial ryegrass infected with endophytes producing different alkaloids. Proceedings of the 48th New Zealand Plant Protection Conference, 229-236.

Rowan DD, Dymock JJ, Brimble MA (1990) Effect of fungal metabolite peramine and analogs on feeding and development of Argentine stem weevil (Listronotus bonariensis). Journal of Chemical Ecology 16, 1683-1695. 